1 Universidade Federal da Bahia (UFBA), Instituto de Saúde Coletiva (ISC),

Programa Integrado de Pesquisa em Planejamento, Gestão e Avaliação Salvador (BA), Brasil. sgb@ufba.br

2 Universidade Federal da Bahia (UFBA), Instituto de Saúde Coletiva (ISC),

Programa Integrado de Pesquisa em Planejamento, Gestão e Avaliação Salvador (BA), Brasil. ligiamvs@ufba.br

\section{A terapia antirretroviral combinada, a política de controle da Aids e as transformações do Espaço Aids no Brasil dos anos 1990}

\author{
Antiretroviral combination therapy, national anti-Aids policy and \\ transformations of the AidsSpace in Brazil in the $1990 \mathrm{~s}$ \\ Sandra Garrido de Barros' ${ }^{\mathbf{1}}$ Ligia Maria Vieira-da-Silva²
}

RESUMO Estudo sócio-histórico, utilizando o referencial teórico de Bourdieu, que analisou as condições de possibilidade para a construção da estratégia de distribuição universal de Antirretrovirais (ARV) no Brasil e as transformações do Espaço Aids. A oferta de ARV não era uma proposta inicial e resultou da pressão dos movimentos sociais, mas também do campo médico e da mídia. Mais tarde, a partir da articulação entre militantes da Reforma Sanitária, foi elaborado o projeto de lei que proporcionou uma situação diferenciada de acesso a ARV, impôs importantes transformações no Espaço Aids e sepultou a possibilidade de uma política de controle da Aids sem acesso ou com acesso restrito a ARV.

PALAVRAS-ChAVE Síndrome da Imunodeficiência Adquirida. Antirretrovirais. Política de saúde. História.

ABSTRACT Socio-historical study, using the theoretical framework of Bourdieu, that analyzed the possibility conditions that allowed the construction of an Antiretroviral (ARV) universal distribution in Brazil and the transformations of the AidsSpace. The supply of ARV drugs was not an initial proposal and resulted from the pressure of social movements, but also from the medical field and the media. Later, from the articulation between militants of the Brazilian Health Reform, the law project that provided a different situation of access to ARV drugs was drafted, imposed major changes in the AidsSpace and buried the possibility of an Aids policy without access or with restricted access to ARV drugs.

KEYWORDS Acquired Immunodeficiency Syndrome. Anti-Retroviral Agents. Health policy. History. 


\section{Introdução}

Entre 1980 e junho de 2014, foram registrados no Brasil 757.042 casos de Síndrome da Imunodeficiência Adquirida (Aids) (BRASIL, 2014). A estimativa de prevalência de Vírus da Imunodeficiência Humana - HIV/Aids em indivíduos de 15 a 49 anos tem-se mantido estável em 0,6\% desde 2004, com cerca de 734 mil indivíduos vivendo com HIV/Aids no Brasil em 2014 (BRASIL, 2014), bem abaixo da expectativa do Banco Mundial em 1993, que previa 1,2 milhão de brasileiros infectados no ano 2000 (WORLD-BANK, 1993). A taxa de detecção também se encontra estabilizada desde 2000 , tendo sido de 20,5 por 100 mil habitantes em 2013 (BRASIL, 2014). Essa tendência à estabilização da epidemia teve início em 1997, coincidindo com a introdução da terapia antirretroviral universal no País (DOURADO ET AL., 2006). Desde 1996, a distribuição gratuita e universal de medicamentos constituiu-se em componente central do programa nacional (GALVÃO, 2000), a despeito do fato de o Banco Mundial, principal agência financiadora das políticas de HIV/Aids no mundo, ter sempre priorizado a prevenção, em detrimento de gastos com assistência e tratamento, considerados caros, em especial nos países em desenvolvimento (GALVÃO, 2000; WORLD-BANK, 1993).

A preocupação com a oferta de medicamentos, desde o final da primeira década de adoção de medidas de controle da Aids, aponta para uma especificidade da política brasileira: a incorporação da diretriz da integralidade da atenção, que busca articular prevenção e tratamento. Característica esta que associada ao enfrentamento dos preços impostos pela indústria farmacêutica contribuiu também para a regulamentação dos medicamentos genéricos no País (LOYOLA, 2008).

Nesse sentido, o Brasil assumiu importante papel na luta pela redução dos preços dos medicamentos antirretrovirais (ARV), evidenciada pela disputa entre 2000 e 2001 no âmbito da Organização Mundial do Comércio (OMC) com os Estados Unidos da América (EUA) pela questão da licença compulsória de medicamentos, pela sua efetivação em 2007 (LOYOLA, 2008) e manutenção, mais recentemente, em 2012 (BRASIL, 2012).

A política nacional de controle da Aids tem sido considerada como de bom desempenho sobre indicadores de morbimortalidade (estabilização da incidência, redução de doenças oportunistas (MALTA; BASTOS, 2008), aumento da média de sobrevida (MALTA; BASTOS, 2008; ROSSI ET AL., 2012), redução da letalidade (ROSSI ET AL., 2012), ainda que apresente limitações no que tange à manutenção e controle do estoque de medicamentos, infraestrutura dos serviços, treinamento adequado para profissionais de saúde, além das questões relacionadas com o financiamento (MALTA; BASTOS, 2008). Também há que se notar que se existe uma tendência nacional a declínio e estabilização da epidemia, a grande diversidade e extensão territorial do País podem mascarar desigualdades regionais (entre 1999 e 2008, Norte e Nordeste ainda apresentavam epidemia em expansão) que devem ser consideradas na implementação das políticas de saúde (TEIXEIRA ET AL., 2014).

Principalmente em função dos resultados obtidos com a distribuição universal de ARV (HACKER ET AL., 2004; OLIVEIRA-CRUZ; KOWALSKI; MCPAKE, 2004), a política brasileira de controle da epidemia de Aids tem sido citada como modelo para outros países em desenvolvimento como Costa Rica, El Salvador, Panamá (PIOT; SECK, 2001) e China (WU ET AL., 2007), assim como para os EUA (GOMEZ, 2010; NUNN, 2009). O President's Emergency Plan for Aids Relief (PEPFAR), projeto do governo norte-americano, iniciado em 2003 para reduzir o sofrimento das pessoas vivendo com HIV/Aids no mundo, por meio do qual os EUA fornecem medicamentos para Aids para países africanos e caribenhos, e a iniciativa 3 by 5 da Organização Mundial da Saúde (OMS), que previa um incremento de 3 milhões de pessoas fazendo uso de ARV no final de 2005, são citados como exemplos de iniciativas que sofreram influência da estratégia brasileira (OKIE, 2006). 
Desde 1991, o programa brasileiro passou a fornecer Zidovudina (AZT) para pessoas vivendo com HIV/Aids; e a partir de 1996, a distribuição universal de ARV, estratégia reconhecida internacionalmente, foi incorporada à política brasileira. De acordo com a literatura, contribuíram para a implementação dessa estratégia a pressão social exercida por inúmeros processos judiciais contra as três esferas do governo para garantir terapia ARV por intermédio do Sistema Único de Saúde (SUS) para pessoas vivendo com HIV/ Aids (BRASIL, 2005; GALVÃO, 2000) assim como manifestações em espaços públicos, ambas as ações promovidas pelas Organizações Não Governamentais (ONGs/Aids), e algumas iniciativas individuais de artistas e intelectuais protestando contra a dificuldade de acesso e $o$ alto custo dos medicamentos (BRASIL, 2005).

Alguns autores (GRANGEIRO; SILVA; TEIXEIRA, 2009; MALTA; BASTOS, 2008) sugerem que os princípios da universalidade do acesso, integralidade das ações e participação social propostos pelo movimento da Reforma Sanitária Brasileira e inseridos na Constituição Federal de 1988 influenciaram a formulação e implementação da resposta brasileira à epidemia da Aids. A despeito dessa ter sido uma influência importante, o complexo processo de formulação e implementação da política de controle da Aids não tem sido analisado orientado por referenciais teóricos e apoiado em fontes orais e documentais.

Dessa forma, o presente estudo busca suprir essa lacuna mostrando como a participação de agentes inseridos no campo médico, o surgimento da terapêutica específica antirretroviral e a pressão dos movimentos sociais no Espaço Aids levaram à ênfase na universalização do tratamento. Com esse objetivo, foram analisadas as condições de possibilidade para a construção da estratégia de distribuição universal de medicamentos ARV no Brasil, bem como as transformações do Espaço Aids decorrentes desse fato, utilizando o referencial teórico da sociologia reflexiva de Bourdieu $(1996,2012)$.

\section{Aspectos teóricos e metodológicos}

Este artigo apresenta os resultados para a década de 1990 de estudo sócio-histórico sobre a resposta brasileira à epidemia da Aids, que compreendeu o período entre 1981, quando foram publicados os primeiros relatos de casos de Aids na literatura científica internacional, e 2001, ano de assinatura do acordo entre Brasil e EUA no âmbito da OMC acerca da licença compulsória de medicamentos, que assegurou a sustentabilidade da estratégia de acesso universal à terapia ARV. A descrição desse espaço de lutas no momento de emergência da política de controle da Aids no País (1981-1989), bem como o detalhamento da metodologia do estudo, já foi objeto de publicação anterior (BARROS; VIEIRA-DA-SILVA, 2016) e subsidia a análise da arquitetura do Espaço Aids no período ora apresentado.

O Espaço Aids brasileiro constituiu-se como espaço de lutas pela organização da resposta à epidemia de Aids, mas também espaço de intervenção sanitária, em que estava em disputa a autoridade de falar sobre o significado da doença, suas formas de prevenção, controle e tratamento. Foi conformado em 1983, inicialmente no estado de São Paulo, onde foram registrados os primeiros casos da doença, envolvendo agentes de diferentes subespaços sociais. No seu desenvolvimento, incorporou movimentos de hemofílicos, talassêmicos e profissionais do sexo e, mais tarde, as ONGs/Aids, tornando-se um espaço de relações complexas, que sofre influência dos campos político, religioso e jurídico (BARROS; VIEIRA-DA-SILVA, 2016).

A dinâmica do Espaço Aids foi analisada em relação às condições históricas de possibilidade. O conceito de espaço social segundo Bourdieu (2012), por vezes usado como sinônimo de campo, corresponde a um microcosmo de relações entre agentes e instituições que possuem um habitus, princípio gerador e organizador de práticas e de representações 
produzidas pelos condicionamentos sociais associados a uma determinada condição, e nas tomadas de posição dele decorrentes e illusio, no sentido de interesse (BOURDIEU, 1996). No caso específico do Espaço Aids, este correspondia a um espaço de lutas no qual articulavam-se agentes de vários campos, com habitus distintos, porém portadores de um interesse em comum: a luta pela organização da resposta à epidemia (BARROS; VIEIRA-DA-SILVA, 2016). Assim os agentes que compunham o Espaço Aids estavam inseridos em diferentes campos sociais: médico, científico, burocrático, político e espaço associativo ou militante (BARROS; VIEIRA-DA-SILVA, 2016).

A análise do espaço social específico, ao interior do qual ocorreu a emergência da política e suas transformações, foi feita por meio da identificação dos principais agentes envolvidos, posições ocupadas no espaço social em questão e tomadas de posição, decisões em relação às questões em disputa no momento histórico estudado. Buscou-se também identificar possibilidades de desenvolvimento das políticas que não chegaram a ser realizadas, denominadas por Bourdieu de 'possíveis mortos' (BOURDIEU, 2012). A importância dessa busca está em afastar a tendência em aceitar que o que ocorreu era o que deveria ter acontecido (BOURDIEU, 2012). Tratase de importante estratégia de ruptura com o senso comum.

Foram ainda considerados, para fins de análise, os processos comuns à emergência das políticas públicas de saúde, propostos por Pinell (2010) a partir da epistemologia e da teoria bourdieusiana. Para este autor, a evolução de uma política de saúde é produto da dinâmica de um complexo jogo social, e sua análise deve considerar: os efeitos concretos da implantação da política (novas instituições, desenvolvimento de grupos profissionais, emergência de novas estruturas associativas) e os obstáculos encontrados; as mudanças no governo (manutenção ou mudança da maioria política); as mudanças que independentemente da política afetam as instituições do campo médico (reformas hospitalares, estudos científicos) ou de outros campos implicados naquela política (educação, justiça etc.) e mais globalmente toda a sociedade (guerras ou mudanças de costumes e nas formas de controle social) (PINELL, 2010).

O estudo apoiou-se em fontes documentais e orais. Foram realizadas entrevistas em profundidade com 33 agentes de diferentes campos ou subespaços sociais envolvidos em diferentes momentos da formulação da Política Nacional de DST/Aids. Os agentes foram identificados pela análise documental e pela metodologia da bola de neve, na qual todos os entrevistados indicam indivíduos a serem entrevistados. Todas as entrevistas foram realizadas pela autora principal, e o tamanho da amostra foi delimitado pela saturação de informações. Para este artigo, foram consideradas 30 entrevistas de indivíduos que participaram do Espaço Aids no momento em que teve início a oferta de AZT pelo Ministério da Saúde (1991) e/ou na formulação da política de distribuição universal de medicamentos ARV (1996) (quadro 1). 
Quadro 1. Perfil dos entrevistados, segundo graduação, pós-graduação, trajetória dominante, relação com Espaço Aids, tomada de posição com relação à distribuição universal de ARV

\begin{tabular}{|c|c|c|c|c|}
\hline $\mathbf{E}$ & Graduação (ano) & Pós-graduação & $\begin{array}{l}\text { Trajetória } \\
\text { dominante }\end{array}$ & $\begin{array}{l}\text { Relação com o } \\
\text { espaço aids }\end{array}$ \\
\hline E1 & Ciências Sociais (1992) & $E$ & B & Profissional \\
\hline E3 & Direito $(S / I)$ & - & $\mathrm{Mi}$ & Profissional/Pessoal \\
\hline E4 & Medicina (1969) & $\mathrm{D}$ & C & Profissional \\
\hline E5 & Ciências Sociais (1988) & $\mathrm{D}$ & $\mathrm{Mi}$ & Profissional \\
\hline E6 & Filosofia (S/I) & - & $\mathrm{Mi}$ & Pessoal HIV+ \\
\hline E7 & Medicina (1976) & $\mathrm{D}$ & C & Profissional \\
\hline E8 & Psicologia Social (1968) & $\mathrm{D}$ & $\mathrm{Mi}$ & Política \\
\hline E9 & Medicina (1965) & $\mathrm{D}$ & C & Pesquisa \\
\hline E12 & Administração (2009) & - & $\mathrm{Mi}$ & Pessoal HIV+ \\
\hline E13 & Hotelaria (1994) & - & $\mathrm{Mi}$ & Pessoal HIV+ \\
\hline E14 & Administração (2004) & M & $\mathrm{Mi}$ & Pessoal \\
\hline E15 & Turismo (S/I) & - & B & Profissional \\
\hline E16 & Medicina (1981) & $\mathrm{D}$ & C & Profissional \\
\hline E17 & Sociologia (S/I) & $E$ & B & Profissional \\
\hline E18 & Matemática (1972) & $\mathrm{D}$ & $\mathrm{Mi}$ & Pessoal HIV+ \\
\hline E19 & Medicina (1961) & $\mathrm{D}$ & C & Profissional \\
\hline E20 & Ciências Sociais (1968) & $\mathrm{D}$ & Mi & Política \\
\hline E21 & Economia (após 2001) & - & B & Profissional \\
\hline E22 & Psicologia (1991) & - & Mi & Pessoal \\
\hline E23 & Medicina (1989) & $\mathrm{D}$ & B & Profissional \\
\hline$E 24^{*}$ & Medicina (1975) & $\mathrm{D}$ & B & Profissional \\
\hline E25 & Ciências Sociais (1987) & M & C & Pessoal \\
\hline E26 & Medicina (1973) & $E$ & B & Profissional \\
\hline E27 & Medicina (197?) & $E$ & B & Profissional \\
\hline E28 & Tecnólogo em processamento de dados (S/I) & $\mathrm{E}$ & B & Profissional \\
\hline E29 & Psicologia (1978) & M & $\mathrm{Mi}$ & Profissional \\
\hline E30 & Medicina (1985) & M & C & Profissional \\
\hline E31 & Medicina (1973) & $\mathrm{D}$ & C & Profissional \\
\hline E32 & Psicologia (1977) & $\mathrm{D}$ & C & Profissional \\
\hline E33 & Psicologia (1985) & $\mathrm{D}$ & $\mathrm{Mi}$ & Política \\
\hline
\end{tabular}

Pós-graduação: E - especialização; M - mestrado; D - doutorado.

Trajetória dominante: B - burocrático; C - científico; Mi - militante.

* Contato por meio de correspondência eletrônica.

A posição ocupada pelos agentes no espaço social global em relação aos diferentes campos foi definida de acordo com o volume de capital científico, burocrático, militante e político, conforme proposta de Vieira-Da-Silva e Pinell (2013) adaptada. A origem social dos agentes foi 
aferida por meio da profissão dos pais e avós; o capital científico foi analisado a partir dos títulos de pós-graduação (mestrado e doutorado), coordenação de projetos de pesquisa e publicações; o capital burocrático, compreendido como poder de definição e imposição de categorias estatais legítimas, foi aferido por meio dos postos ocupados na burocracia estatal; já o capital militante foi aferido pelas posições na administração das ONGs (BARROS; VIEIRA-DASILVA, 2016). Foi ainda caracterizado o sentido dominante da trajetória no Espaço Aids (se nos campos científico ou burocrático ou ao interior do espaço associativo ou militante); indicadores de disposições políticas (filiação, militância ou voto em partido político, participação no movimento sanitário, em movimentos profissionais e sociais); disposições sobre a organização do sistema de saúde e disposições específicas sobre a Aids.

Foi feita uma triangulação entre as fontes a fim de reunir elementos capazes de caracterizar as condições de possibilidade históricas para a formulação da estratégia de distribuição universal de medicamentos ARV no Brasil.

Todos os entrevistados assinaram o termo de consentimento informado e manifestaram o acordo com a divulgação do seu nome por tratar-se de informações relacionadas com o exercício de cargos ou posições públicas. O projeto de pesquisa foi aprovado pelo Comitê de Ética em Pesquisa do Instituto de Saúde Coletiva da Universidade Federal da Bahia (CAAE 0061.0.069.000-10).

\section{Resultados e discussão}

\section{Transformações no Espaço Aids e a oferta inicial de medicamentos}

Os anos de 1985 a 1989 no Brasil foram um período de construção da política nacional de controle da Aids (BARROS; VIEIRA-DA-SILVA, 2016; LAURINDO-TEODORESCU; TEIXEIRA, 2015), baseada principalmente em ações de vigilância epidemiológica e medidas preventivas, ante a ausência de tratamento medicamentoso eficaz, no qual a Comissão Nacional de Aids (CNAIDS), criada em 1986, caracterizou-se como importante espaço de definições técnicas e políticas a esse respeito (BARROS; VIEIRA-DASILVA, 2016). Embora seu papel fosse consultivo, diversos documentos discutidos e propostos pela comissão formaram a base do discurso oficial (BRASIL, 2003). As suas discussões pautavam a elaboração de recomendações técnicas que eram adotadas pelo Programa ou na constituição de subcomissões de especialistas que incluíam membros e não membros da comissão para a definição de normas, tendo como base essas recomendações, como no caso da definição dos critérios para uso da zidovudina (AZT) (BRASIL, 1994).

Com o surgimento do AZT, em 1987, teve-se a primeira possibilidade de tratamento da Aids. A distribuição de medicamentos para doenças oportunistas que acometiam pacientes com HIV acontecia desde 1988 pelo Ministério da Saúde, de forma muito tímida. A partir de 1989, algumas unidades da federação, de forma incipiente e, em especial, devido às ações judiciais, começaram a disponibilizar o AZT na rede pública (BRASIL, 2005). O Ministério da Saúde só iniciaria a distribuição de AZT ampliando a oferta de medicamentos para o tratamento da Aids para todos os estados do País no início da década de 1990.

O período de 1990 a 1992 foi marcado pela política neoliberal e pelo desfinanciamento do SUS (PAIM, 2008). Particularmente, no que diz respeito ao Programa Nacional de Aids, esse período foi marcado pela quebra nos canais de comunicação anteriormente estabelecidos com as ONGs, secretarias estaduais, médicos e pesquisadores, inclusive com a desativação da CNAIDS, em decorrência da mudança de toda a equipe gestora da política, bem como seu quadro técnico-administrativo, o que também foi destacado por Laurindo-Teodorescu e Teixeira (2015). As ONGs/Aids criticavam a omissão do governo 
e a campanha educativa 'Se você não se cuidar, a Aids vai te pegar', considerada disseminadora de pânico e medo (GALVÃo, 2000).

Paradoxalmente, dois eventos ocorridos entre 1990 e 1992 implicaram transformações importantes que estruturaram a base para a consolidação da política nacional de Aids na gestão seguinte:

- O início da distribuição na rede pública de AZT, pentamidina e ganciclovir em 1991 (LAURINDO-TEODORESCU; TEIXEIRA, 2015; TEIXEIRA, 1997);

- O início das negociações para o primeiro acordo de empréstimo no Banco Mundial.

Quando o programa de Aids passou a ser prioridade no Ministério da Saúde [em 1991], sabe, aí nós fomos incluídos para o financiamento do Banco Mundial. (E7, 07-08/12/2011).

Uma outra coisa que o Alceni fez foi aceitar uma proposta do Banco Mundial para firmar um acordo de empréstimo para o ' $P N$ ' [Programa $\mathrm{Na}$ cional]. Ele indicou [...] o Edmur Pastorello, para negociar junto ao Banco. O Edmur me chamou. Foi o Edmur e eu que fizemos a carta de intenção para apresentar ao Banco, com 'palpites' do Pedro Chequer. [...] o Acordo de Empréstimo com o Banco Mundial só foi assinado, que passa pelo Senado, o Ministério da Fazenda e tudo mais, pelo Ministro Adib Jatene, mas foi uma iniciativa do Ministro Alceni Guerra. A verdadeira iniciativa, por parte do Banco Mundial, foi da Maureen Lewis, uma norte-americana que passou a adolescência aqui no Brasil. (E9, 05/05/2011).

Na época, Edmur Pastorello, que é da USP, trabaIhava como assessor do ministério para o Alceni Guerra. Ele convidou o Euclides. Eu era uma pessoa [...] antes eu trabalhei [...] como diretor do Cenepi [Centro Nacional de Epidemiologia], na época do cólera. E como o ministro Alceni Guerra quis esconder os óbitos, eu denunciei, [...] ele me mandou para o Acre, não podia me demitir porque eu era estável no governo e aí o Euclides me chamou escondido porque ele não podia saber que eu estava envolvido. Aí se fez as duas, três primeiras páginas do que seria o embrião do projeto de acordo do Banco Mundial, que o Dr. Adib Jatene assumiu. [...]. Nós fizemos uma reunião no prédio da Funasa [Fundação Nacional de Saúde], no anexo que ficou a Funasa, onde depois passou a ser Cenepi [...]. E nós discutimos alguns princípios e tal, que o Pastorello utilizou e depois o Pastorello continuou com o Adib porque como era da USP, terminou continuando e a coisa aconteceu do primeiro acordo de empréstimo. (E27, 03/08/2011).

Nesse sentido, pode-se inferir que a conjuntura político-administrativa do Estado Brasileiro não teve uma relação direta com a política de controle da Aids nesse período. A trajetória dos agentes e a criação de um Espaço Aids com relativa autonomia, do qual participavam militantes de associações específicas de luta contra a Aids, do movimento homossexual, de hemofílicos e do movimento sanitário, bem como médicos clínicos e pesquisadores, permitiram que a política de controle da Aids incorporasse o tratamento com medicamentos além das ações preventivas previstas inicialmente. Estudo recente evidencia que o tratamento com ARV, associado a estratégias preventivas (aconselhamento e fornecimento de preservativos), reduz a transmissão do HIV em 96\% (COHEN ET AL., 2015).

A oferta de medicamentos ARV pelo Ministério da Saúde não era uma proposta inicial, nem em 1988 na gestão de Lair Guerra (DROGA... 1988), nem no plano de governo do então candidato à presidência da República Fernando Collor de Mello. Em 1989, em consulta realizada pelo Grupo de Apoio à Prevenção da Aids (Gapa-SP) a cinco dos candidatos a presidente (CANDIDATOS... , 1989), Collor considerava que a aquisição do AZT deveria ser encargo dos doentes, das empresas, das instituições privadas de assistência e de fontes não exclusivamente governamentais.

A decisão em adquirir e disponibilizar medicamentos para a Aids na rede pública sem uma articulação prévia com outros 
setores do governo, como o Ministério do Orçamento, Planejamento e Gestão, teria sido do Ministro Alceni Guerra (E7). A pressão da mídia e das ONGs, bem como a figura de um médico clínico na gestão do Programa Nacional, com experiência no tratamento de pacientes com HIV/Aids na Universidade da Califórnia, em uma realidade diferente da brasileira, com acesso a medicamentos para o tratamento dos doentes, contribuiu para o início da implantação de uma política nacional de acesso a medicamentos para o tratamento da Aids (E7).

Eu fiz uma previsão de custos e de remédios, eu tinha isso pronto. No dia que o [ministro] Alceni [Guerra] me chamou lá porque a televisão estava lá e ia cobrar dele e ele me perguntou quanto custaria os remédios, eu disse '30 milhões de dólares'. [...] A nossa média de sobrevida era seis meses. [...] Eu vi as pessoas morrerem aos quilos, não tinha remédio, não tinha nada, não é $A Z T$, eu estou falando de remédio, não tinha remédio pra tuberculose pras pessoas, [...] você via as pessoas morrerem por falta de remédio! [...] antes do AZT, eu já tinha conseguido aprovar pra tratar todas as infeccõoes dos doentes de Aids e isso foi assim uma mudança enorme. [...]. (E7, 07-08/12/2011).

A conjuntura sanitária daquele momento, de desfinanciamento e retrocesso na implementação de projetos de mudança de modelos assistenciais, possivelmente influenciaram os limites da iniciativa de incorporação da distribuição do AZT para doentes com Aids.

\section{Novas correlações de forças e novas instâncias de participação}

Entre 1992 e 1995, a primeira gestora do Programa Nacional retornou à sua coordenação, bem como toda a sua equipe técnica. Com a maior estruturação da política nacional, bem como os avanços no saber médico sobre a doença e seu tratamento, entre 1992 e 1993, o Espaço Aids tornou-se mais complexo. Surgiram outras instâncias de assessoramento ao Programa Nacional: comitê de vacinas, comissão para estudos e ações no sistema penitenciário, comitê de pesquisa e um setor específico de articulação com as ONGs. Alguns entrevistados (E1, E3, E13) relacionaram o surgimento dessas novas instâncias à complexidade que a resposta governamental adquiriu; à entrada de novos agentes no Espaço Aids e aos avanços no saber médico acerca da doença, bem como a formação de uma expertise em diversas áreas. A especialização desse espaço, seja no campo médico (surgimento de uma nova especialidade - a infectologia, desenvolvimento de testes diagnósticos e medicamentos, e a realização de estudos de vacinas) ou no burocrático (técnicos que fizeram carreira assumindo diferentes posições na gestão da política de Aids, alguns inclusive oriundos dos movimentos sociais), levou ao surgimento de novas instâncias de participação e articulação do Estado com os demais agentes interessados no controle da epidemia. Essa nova configuração refletia as disputas ao interior do Espaço Aids entre o discurso médico, sanitarista e militante e levou à criação de instâncias técnico-científicas (Comitê de Vacinas, Comitê Assessor para Terapia Antirretroviral, Comitê Técnico Assessor de Gestores). A diversificação e especialização das comissões tornava mais ágil a discussão dos processos, mas, por outro lado, o desmembramento em diferentes fóruns de decisão da política pulverizou o poder, antes concentrado na CNAIDS.

O Comitê Assessor para Terapia Antirretroviral, instalado a partir de 1996, foi caracterizado como uma "comunidade de especialistas" no estudo realizado por Lago e Costa (2017, P. 1487), com dominância do campo médico, em especial infectologistas, que influenciavam fortemente a tomada de decisão. O estudo verificou ainda que apenas a partir das reuniões para discussão do consenso 2002/2003 houve participação de 
representantes da sociedade civil, apesar do protagonismo dos movimentos sociais para o desenvolvimento da resposta à epidemia da Aids no País (LAGO; COSTA, 2017).

A arquitetura do Espaço Aids brasileiro mostrou-se bastante dinâmica no período estudado (1981-2001). Novos grupos, como hemofílicos e outros receptores de sangue e hemoderivados, profissionais do sexo e pessoas vivendo com HIV/Aids, foram incorporados ao espaço militante a partir das mudanças observadas no comportamento epidemiológico da doença (BARROS; VIEIRA-DASILVA, 2016). Mais especificamente entre 1990 e 2001, pode-se destacar o estabelecimento de relações com agentes e instituições de outros espaços, como a indústria farmacêutica, organismos internacionais externos ao setor saúde, a exemplo da OMC, e um maior envolvimento do poder legislativo (campo político) com a criação da Frente Parlamentar de Luta Contra a Aids ao final do período.

O financiamento do Banco Mundial por meio de acordos de empréstimo, a partir de 1993, apesar de polêmico e de ter suscitado reações diversas, foi considerado como facilitador da expansão e consolidação das ONGs/Aids, bem como contribuiu para a estruturação inicial de uma rede de serviços de saúde e apoio diagnóstico, e para a capacitação técnica de profissionais, questões fundamentais à universalização do tratamento, viabilizada por intermédio de recursos do tesouro nacional.

[...] [os acordos de empréstimo] representaram e representam ainda hoje a execução da política. Eles representaram a possibilidade de ter financiamento de projetos de diversas áreas. [...] os empréstimos vêm diminuindo ao longo do tempo, mas eu acho que existem indicadores de que ele de fato foi usado de uma forma que hoje a gente tem resultados positivos em várias áreas: capacidade instalada, formação de recursos humanos, no Brasil inteiro, nas mais diversas áreas desde a área do cuidado, da epidemiologia, da prevenção. (E16, 05/09/2011).

[...] só prevenção, prevenção, prevenção, nada de tratamento, tratamento não valia a pena, que era caro e os países não iam ter condições disso. [...] Era a lógica do Banco e se isso era ruim, por outro lado, foi bom porque evitou que se utilizasse recurso do banco para comprar remédio, e isso criou o embrião da garantia do Tesouro Nacional. [...]. (E27, 03/08/2011).

A ampliação da contrapartida governamental nos dois últimos acordos diminuiu o impacto na redução do montante de recursos repassados pelo Banco Mundial e assegurou maior autonomia, bem como o aumento da sustentabilidade e independência financeira da política brasileira de controle da Aids (quadro 2).

Quadro 2. Acordos de empréstimo para o controle da Aids, período de aplicação, montante total, participação do Banco e do governo brasileiro, 1993-2014

\begin{tabular}{lllll}
\hline Acordo de empréstimo & $\begin{array}{l}\text { Período } \\
\text { (assinatura-encerramento) }\end{array}$ & $\begin{array}{l}\text { Montante total } \\
\text { (em US\$) }\end{array}$ & $\begin{array}{l}\text { Banco } \\
\text { (em US\$) }\end{array}$ & $\begin{array}{l}\text { Governo brasileiro } \\
\text { (em US\$) }\end{array}$ \\
\hline Aids I & $1993-1998$ & 250 milhões & 160 milhões & 90 milhões \\
Aids II & $1998-2003$ & 300 milhões & 165 milhões & 135 milhões \\
Aids III & $2003-2007$ & 200 milhões & 100 milhões & 100 milhões \\
Aids-SUS & $2010-2014$ & 200 milhões & 67 milhões & 133 milhões \\
\hline
\end{tabular}

Fonte: World-Bank $(1993,1997,2004,2010)$. 


\section{A universalização do acesso a medi- camentos e novas transformações do Espaço Aids}

O acesso universal à terapia antirretroviral foi alcançado por meio de um processo para o qual contribuíram médicos, docentes e pesquisadores, sanitaristas e, em especial, militantes das associações específicas de luta contra a Aids.

As manifestações em espaços públicos exigindo a distribuição de medicamentos pelo Estado começaram em 1995, promovidas principalmente pelas ONGs/Aids, mas também por artistas, em iniciativas mais individuais (BRASIL, 2005). Desde o início de 1996, proliferaram as ações de demanda de medicamentos para portadores de HIV/Aids, promovidas pelas assessorias jurídicas das ONGs, inspiradas no modelo do Gapa-SP e fomentadas pelo financiamento dos acordos de empréstimo (E3, E33) (BRASIL, 2005).

A divulgação, na XI Conferência Internacional de Aids de Vancouver, dos resultados obtidos com um coquetel de três drogas, contendo um inibidor da protease, e a decisão favorável da justiça de São Paulo à ação do Gapa-SP, em nome de uma professora, serviram de impulso para novas ações judiciais demandando fornecimento de inibidores da protease (FELTRIN, 1996). Até aquele momento, a única cidade do País que fornecia por conta própria o coquetel era a cidade de Santos, no estado de São Paulo. Vale ressaltar que tal ação foi iniciada na gestão de David Capistrano, médico militante do movimento sanitário brasileiro, na saúde do município.

Em reportagem da Folha de São Paulo do dia 13 de julho de 1996 (IMPORTAÇÃo..., 1996), foram identificadas três concepções sobre a distribuição universal de medicamentos ARV: 'a favor', que considerava um direito do portador de HIV/Aids; 'administração racional dos recursos', que justificava a adoção da estratégia pelos critérios epidemiológicos, mas considerava que limitações orçamentárias do governo não permitiam a sua implantação; e 'contra a medida', que consideravam uma medida discriminatória aos portadores de outras enfermidades:

a) A estratégia era defendida pelo médico infectologista David Uip, doutor em Doenças Infecciosas e Parasitárias pela USP e diretor técnico do serviço de epidemiologia e desenvolvimento de qualidade, do Instituto do Coração do Hospital das Clínicas da Faculdade de Medicina da Universidade de São Paulo. O médico destacava que o custo médio elevado por paciente/mês representava um investimento de $\mathrm{R} \$ 143$ milhões, mas também aumento, qualidade e dignidade da sobrevida dos pacientes, bem como redução das hospitalizações e de medicamentos necessários, um ponto de vista do público, do universal, mas que também representa um olhar para o clínico e o individual;

b) A administração racional de recursos era expressa por Luiz Roberto Barradas Barata, médico sanitarista e secretário interino de saúde do estado de São Paulo, que pontuava os critérios epidemiológicos como magnitude e transcendência da doença e a eficácia do tratamento como razões que justificavam a adoção da estratégia. Todavia considerava que a realidade financeira da saúde pública não permitia um gasto da ordem de $\mathrm{R} \$ 20$ mil por paciente/ano, argumentos técnico científicos;

c) E o médico, deputado federal pelo PSDB-SP e diretor-presidente da Blue Life Assistência Médica, Ayres da Cunha, um representante do polo do mercado, argumentava contra a estratégia, considerando que a questão da Aids era tratada de forma paternalista e que a distribuição gratuita de medicamentos seria uma medida discriminatória e ilegítima com os pacientes de outras patologias. Posição que podia representar os interesses da medicina supletiva pelos recursos do SUS. 
Essas concepções correspondem a uma divisão ao interior do campo médico e tinham adesões de outros participantes do Espaço Aids, aparecendo na fala de alguns entrevistados, seja refletida na sua própria concepção ou no relato de posicionamentos com os quais não concordavam, porém, com maior abrangência, relacionada não apenas com os medicamentos, mas com toda a questão da assistência à saúde. Entre eles, talvez pela própria relação com o desenvolvimento da política de controle da Aids no País, a fala parece mais polarizada entre o direito dos portadores de HIV/Aids ao medicamento e a discriminação em relação aos portadores de outras enfermidades, mas não no sentido de negar o direito de acesso a medicamentos aos primeiros, mas de garantir o direito à assistência à saúde aos últimos (E11, E13, E18, E31). Outra posição destacada por um dos entrevistados era uma posição preconceituosa, homofóbica (E33).

[...] eu acho que isso é uma obrigação do Estado, [...] existia muitas posições contrárias, que isso era um absurdo num país onde você não tinha as questões mínimas de garantia de direitos, por que é que tinha que dar remédio pra pessoas promíscuas? Você ouvia isso de políticos. (E13, 02/08/2011).

[...] eu me lembro de médicos que também atendiam tuberculose e diziam: 'não, porque meus pacientes de tuberculose não têm remédios, porque só tem remédios para Aids'. Não tem nada a ver uma coisa com a outra. (E18, 18/06/2011).

[...] Eu acho que a Política Nacional de Aids ela significa para o SUS um exemplo de como a gente deve trabalhar para as outras doenças. [...] Esse exemplo deveria ser pego, para a gente trabalhar com as outras, principalmente, com as negligenciadas. [...] eu acho que as outras têm que se igualar para que a gente possa ter um resultado parecido. (E11, 04/08/2011).

[...] para a política da Aids, eu acho que o que o público em geral necessita é o que já existe. É atendimento quando e onde eles precisam. Você não vê um indivíduo com HIV rodando por aí dizendo que não foi atendido. Isso é uma coisa inédita. Porque você vê gente com lepra dizendo que não foi atendido. [...] Então para Aids eu não sinto necessidade de mais do que já existe em termos operacionais. [...]. (E31, 20/06/2011).

$\mathrm{O}$ projeto de lei que propôs o acesso universal aos medicamentos para Aids, de autoria do senador José Sarney, representava os anseios de diversos grupos, em especial da sociedade civil organizada, que já vinha promovendo mobilizações nesse sentido. Sua concretização teria resultado de uma articulação entre ativistas envolvidos no movimento da Reforma Sanitária Brasileira do estado do Rio de Janeiro e da Bahia, e com algum volume de capital político, como o sociólogo Betinho, o médico sanitarista Sergio Arouca e o chefe de gabinete do senador, o médico Carlos Sant'Anna, deputado federal pelo Partido do Movimento Democrático Brasileiro (PMDB) nas legislaturas de 19821985 e 1986-1989, Ministro da Saúde no período de março de 1985 a fevereiro de 1986 e Ministro da Educação entre janeiro de 1989 e março de 1990. Essa articulação foi evidenciada por três diferentes entrevistados: "O Sarney, ele foi procurado pelo próprio Betinho" (E6, 03/08/2011); "Quem redigiu o projeto foi Carlos Sant'Anna, que era assessor do Sarney” (E9, 05/05/2011).

A ideia original foi de Sergio Arouca, provavelmente conversando com Betinho. Porque Arouca era deputado pelo Rio. Aí levou, como se davam muito bem Arouca e Carlos, [...] eles se conversavam, se apoiavam. [...] Carlos sabia escrever lei muito bem. [...] Todo mundo reconhecia isso. Então muitos deputados, e Arouca também foi lá, levavam para ele para ver a forma, o processo legislativo, aquele negócio todo. [...]. Então ele viu tudo e bolou com Carlos uma estratégia que disse assim: 'Se você deixar Sarney apresentar provavelmente é mais forte'. Mas a ideia original 
foi de Arouca. E foi de Arouca trazido do Rio, que eu acho que foi Betinho. [...] Quem levou para Carlos a proposta, a ideia inicial foi Arouca, [...] Então eu imagino que nesse desenho da estratégia para fazer com que o projeto de lei, chegasse à Câmara, Carlos deve ter negociado com Arouca, que isso seria através de Sarney. Então Carlos entrou nisso no sentido de sensibilizar Sarney para fazer lá. Mas a ideia original foi essa. (E10, 14/07/2011).

A tramitação do projeto no poder legislativo durou apenas quatro meses (12 de julho a 13 de novembro de 1996), haja vista que o projeto tratava de uma reafirmação dos direitos constitucionais, ainda que enfrentasse oposição de alguns setores (AZEVEDO, 2010). A lei proporcionou uma situação diferenciada de acesso aos medicamentos ARV em relação ao acesso a outros medicamentos no SUS e impôs importantes transformações no Espaço Aids brasileiro: a crítica mais ácida das ONGs com relação à política quase desapareceu, sendo a principal demanda o cumprimento do estabelecido na legislação; o discurso oficial favorável à universalização do tratamento passou a ter uma posição dominante no Espaço Aids e a política brasileira ganhou reconhecimento internacional.

A luta pela sustentabilidade da estratégia de acesso universal aos ARV contribuiu também para a regulamentação dos medicamentos genéricos no Brasil (LOYOLA, 2008) e influenciou o posicionamento político internacional do País na disputa com a indústria farmacêutica internacional pela redução dos preços dos medicamentos ARV. Essa foi umas das mais importantes disputas que aliou médicos sanitaristas, pesquisadores, agentes do campo burocrático e usuários contra a indústria farmacêutica.

A política agressiva adotada pelo Brasil para a redução dos preços dos medicamentos para Aids levou a uma disputa acerca da licença compulsória de medicamentos com os EUA na OMC em 2000. Em junho de 2001, o acordo entre os dois países admitiu a possibilidade de quebra de patente em questões de saúde pública de países em desenvolvimento (WTO, 2001A). Tal fato levou o País a assumir a liderança da negociação com a OMC para que o acordo sobre Aspectos dos Direitos de Propriedade Intelectual Relacionados ao Comércio (Acordo Trips, do inglês TradeRelated Aspects of Intellectual Property Rights), que estabelece padrões mínimos no âmbito do direito internacional relacionados com as patentes, inclusive de medicamentos, não fosse uma barreira para o acesso aos medicamentos, considerados uma questão de direitos humanos. Esse processo culminou com a assinatura da Declaração sobre o Acordo Trips e saúde pública em 2001, conhecida como Declaração de Doha (WTO, 2001B).

\section{Considerações finais}

As transformações no Espaço Aids entre os anos 1983 e 2001, articuladas à democratização do País e aos desdobramentos da Reforma Sanitária Brasileira nesse período, resultaram na operacionalização de uma política com características consideradas exemplares, como a universalidade e a não discriminação. A implementação dessa política materializou na prática o princípio do SUS de integralidade. O protagonismo do Espaço Aids, nesse sentido, decorreu de uma mobilização específica de profissionais de saúde, militantes da Reforma Sanitária Brasileira e ativistas das ONGs/Aids cuja competente articulação com o campo jurídico e político possibilitaram a universalização do tratamento.

Cabe um destaque para a qualidade da participação social. As pessoas com HIV/ Aids tornaram-se agentes da sua própria história, não restringindo a sua participação ao subespaço militante, mas assumindo posições também no campo burocrático. Esse trânsito ao interior da burocracia estatal foi garantido pelo financiamento internacional, que permitiu a contratação de profissionais 
por meio de projetos, garantindo um corpo técnico qualificado e diversificado, engajado na luta pelo controle da epidemia. $\mathrm{O}$ ativismo da Aids profissionalizou-se, superando a fase do voluntariado.

A Lei $n^{\circ}$ 9.313/1996 garantiu o acesso universal a medicamentos para o tratamento da Aids, sepultando a possibilidade de implementação de uma política de controle da Aids no Brasil apoiada unicamente na prevenção, seguindo as recomendações das agências internacionais para países em desenvolvimento àquela época. Esse fato pode ser considerado um 'possível morto', nesse caso indesejável e superado.

O engajamento político-militante profissional, associado à luta contra a Aids no Brasil, não encontra precedentes na história da saúde no País. O fato de poder perceber um reflexo das propostas da Reforma Sanitária Brasileira no movimento de luta contra a epidemia da Aids (Espaço Aids) acontece porque a história da política de Aids não se desvincula da construção histórica de um SUS cujas diretrizes incluem a integralidade, a justiça, a equidade e a universalidade.

Em que pese o relativo sucesso da política nacional e mesmo a vanguarda assumida pelo País, na opinião de diversos militantes/ ativistas e mesmo de profissionais do campo burocrático, a sua continuidade e sustentabilidade não têm sido asseguradas. A política da Aids compartilha dos mesmos problemas do SUS e requer para a sua preservação e ampliação a superação do crônico desfinanciamento da saúde no Brasil.

\section{Referências}

A IMPORTAÇÃO de remédios contra a Aids deve ser prioridade do Ministério da Saúde? Folha de São Paulo, São Paulo,13 jul. 1996.

AZEVEDO, M. G. S. L. C. Acesso gratuito aos medicamentos antirretrovirais: contribuição do legislativo para a política brasileira de combate à Aids. (Especialização), Centro de Formação, Treinamento e Aperfeiçoamento (Cefor), Câmara dos Deputados, Brasília, DF, 2010.

BARROS, S. G. D.; VIEIRA-DA-SILVA, L. M. A gênese da política de luta contra a Aids e o Espaço Aids no Brasil (1981-1989). Rev. Saúde Pública, São Paulo, v. 50, 2016. Disponível em: <http://www. scielo.br/scielo.php?script=sci_arttext\&pid=S0034$-89102016000100227 \& \operatorname{lng}=$ pt\&nrm=iso $>$. Acesso em:
31 jan. 2017.

BOURDIEU, P. Razões práticas: sobre a teoria da ação. Campinas: Papirus, 1996

Sur l'État: cours au Collège de France 1989-1992. Paris: Éditions Raisons d'agir, Éditions Seuil, 2012.

BRASIL. A Comissão Nacional de Aids: a presença do passado na construção do futuro. Brasília, DF: Ministério da Saúde,2003.

Decreto $\mathrm{n}^{\circ} 7.723$, de 4 de maiode 2012. Diário

Oficial [da] República Federativa do Brasil, Poder

Executivo, Brasília, DF, 07 maio 2012. Seção 1, p.1. Ministério da Saúde. Secretaria de Vigilância 
em Saúde. Departamento de DST, Aids e Hepatites Virais. Boletim Epidemiológico: Aids e DST. Brasília, DF: Ministério da Saúde, ano III, 2014.

Ministério da Saúde. Secretaria de Vigilância em Saúde. Programa Nacional de DST e Aids. Comissão Nacional de Aids: 1986-1994. Brasília, DF: Ministério da Saúde, 1994.

Ministério da Saúde. Secretaria de Vigilância em Saúde. Programa Nacional de DST e Aids. O remédio via justiça: um estudo sobre o acesso a novos medicamentos e exames em HIV/Aids no Brasil por meio de ações judiciais. Brasília, DF: Ministério da Saúde, 2005.

CANDIDATOS prometem fiscalizar qualidade do sangue. Folha de São Paulo, São Paulo,11 out. 1989.

COHEN, M. et al.Final results of the HPTN 052 randomized controlled trial: antiretroviral therapy prevents HIV transmission. Journal of the International AIDS Society, v. 18, supl.4, p. 15, 2015.

DOURADO, I. et al. Tendências da epidemia de Aids no Brasil após a terapia anti-retroviral. Rev. Saúde Pública, v. 40, supl., p. 9-17,2006.

DROGA importada para tratamento da Aids será liberada em 20 dias. Folha de São Paulo, São Paulo,11 out. 1988.

FELTRIN, R. Gapa tenta coquetel anti-Aids para mais 20. Folha de São Paulo, São Paulo, 12 jul. 1996.

GALVÃO, J. AIDS no Brasil: a agenda de construção de uma epidemia.São Paulo: Editora 34, 2000.

GOMEZ, E. J. What the United States can learn from Brazil in response to HIV/AIDS: international reputation and strategic centralization in a context of health policy devolution. Health Policy and Planning, Oxford, v. 25 , n. 6 , p. 529-541, 2010.

\section{GRANGEIRO, A.; SILVA, L. L. D.; TEIXEIRA, P. R.}

Resposta à Aids no Brasil: contribuições dos movimentos sociais e da reforma sanitária. Rev Panam. Salud Publ.,Washington, DC, v. 26, n. 1, p. 87-94, nov. 2009.
HACKER, M. A. et al. Highly active antiretroviral therapy in Brazil: the challenge of universal access in a context of social inequality. Revista Panamericana de Salud Publica-Pan American Journal of Public Health, Washington, DC, v. 16, n. 2, p. 78-83, ago. 2004.

LAGO, R. F.; COSTA, N. R. Comunidades de especialistas e formação de interesses no programa de Aids no Brasil. Ciência \&t Saúde Coletiva, Rio de Janeiro, v. 22, n. 5, p. 1479-1488, 2017.

LAURINDO-TEODORESCU, L.; TEIXEIRA, P. R. Histórias da Aids no Brasil, 1983-2003: as respostas governamentais à epidemia de Aids. Brasília, DF: Ministério da Saúde, v. 1, 2015.

LOYOLA, M. A. Medicamentos e saúde pública em tempos de AIDS: metamorfoses de uma política dependente. Ciência \&t Saúde Coletiva, Rio de Janeiro, v. 13, n. supl., p. 763-778, 2008.

MALTA, M.; BASTOS, F. I. Aids: prevenção e assistência. In: GIOVANELLA, L.; ESCOREL, S. et al (Ed.). Políticas e Sistema de Saúde no Brasil. Rio de Janeiro: Fiocruz, 2008. p. 1057-1088.

NUNN, A. The politics and history os Aids treatment in Brazil. Nova Iorque: Springer Science, 2009.

OKIE, S. Fighting HIV: Lessons from Brazil. New England Journal of Medicine, v. 354, n. 19, 2006. Disponível em: <http://www.nejm.org/doi/ full/10.1056/NEJMp068069\#t=article>. Acesso em: 20 out. 2012.

OLIVEIRA-CRUZ, V.; KOWALSKI, J.; MCPAKE, B. Viewpoint: The Brazilian HIV/AIDS 'success story' - can others do it? Tropical Medicine \& International Health, v. 9, n. 2, p. 292-297, fev. 2004.

PAIM, J. Reforma Sanitária Brasileira: contribuição para compreensão e crítica. Salvador, Rio de Janeiro: EDUFBA, Fiocruz, 2008.

PINELL, P. Análise sociológica das políticas de saúde. Rio de Janeiro: Fiocruz, 2010. 
PIOT, P.; SECK, A. M. C. International response to the HIV/AIDS epidemic: planning for success. Bulletin of the World Health Organization, v. 79, n. 12, p. 1106-1112,2001. Disponível em: <http://www. scielosp.org/scielo.php?script=sci_arttext\&pid=S0042$-96862001001200006 \& \operatorname{lng}=\mathrm{en} \& \mathrm{nrm}=\mathrm{iso} \& \operatorname{lng}=\mathrm{en}>$. Acesso em: 20 out. 2012.

ROSSI, S. M. G. D. et al. Impacto da terapia antirretroviral conforme diferentes consensos de tratamento da Aids no Brasil. Revista Panamericana de Salud Pública, v. 32, p. 117-123, 2012. Disponível em: <http://www. scielosp.org/scielo.php?script=sci_arttext\&pid=S1020$-49892012000800005 \& n r m=i s o>$. Acesso em: 27 abr. 2013.

TEIXEIRA, P. R. Políticas públicas em AIDS. In: PARKER, R. (Org.). Políticas, instituições e AIDS: enfrentando uma epidemia no Brasil. Rio de Janeiro: Jorge Zahar Ed., ABIA, 1997. p. 43-68.

TEIXEIRA, T. R. A. et al. Social geography of AIDS in Brazil: identifying patterns of regional inequalities. Cadernos de Saúde Pública, Rio de Janeiro, v. 30, p. 259-271, 2014
VIEIRA-DA-SILVA, L.; PINELL, P. The Genesis of Collective Health in Brazil. Sociology of Health \& Illness, Boston, v. 36, n. 3, p. 432-46, mar.2014.

WORLD-BANK. Human Resources Division Country Department I. Staff Appraisal Report: Brazil Aids and SDT control project. Washington, DC: World Bank, 1993.

WORLD TRADE ORGANIZATION. Brazil - Measures affecting patent protection. Notification of Mutually Agreed Solution. Genebra: WTO, 2001a.

Declaration on the TRIPS agreement and public health. Adopted on 14 november 2001. Doha: WTO, $2001 b$.

WU, Z. Y. et al. Evolution of China's response to HIV/ AIDS. The Lancet, Edinburgo, v. 369, n. 9562, p. 679690, 2007.

Recebido para publicação em abril de 2017 Versão final em julho de 2017

Conflito de interesses: inexistente

Suporte financeiro: Fundação de Amparo à Pesquisa do Estado da Bahia (Fapesb - 020/2010 - Programa Pesquisa para o SUS: Gestão Compartilhada em Saúde PPSUS/2010 - MS/CNPq/ Fapesb/Sesab) 